\title{
Fear of Crime and Affective Ambiguities in the Night-time Economy
}

\author{
Jelle Brands, Tim Schwanen and Irina van Aalst
}

[Paper first received, April 2012; in final form, August 2013]

\begin{abstract}
This article analyses fear of crime in the night-time economy as an event that emerges from, and unfolds as part of, the on-going encounters with human and non-human elements in particular places. A conceptual approach to understanding fear of crime is elaborated that highlights the role of ambiguity, meaning that a particular element does not have stable, well-determined effects on fear of crime, and the importance of thinking of fear as the folding of immediate futures and the past into the experienced present. Drawing on empirical research with university students in Utrecht, the Netherlands, the article explores how lighting, policing and the presence of 'undesired others' affect fear. Multiple forms of ambiguity are shown to exist, suggesting that interventions in the built environment and zero-tolerance policing tactics are unlikely to reduce fear of crime in the night-time economy as much as past research, influential policy and media discourses have suggested.
\end{abstract}

Keywords: ambiguity, assemblage, fear of crime, night-time economy, policy interventions

\section{Introduction}

In recent decades, cities have become more proactive in stimulating the local economy by trying to make their city centres sites of consumption and pleasure, and the creation of a vibrant night-time economy (NTE) has been an important ingredient of local governments' attempts to improve a city's attractiveness and liveability (Chatterton and Hollands, 2003; Roberts and Eldridge, 2009). The mitigation of fear of crime has come to play an important role in such attempts as it is widely believed that the

Jelle Brands and Irina van Aalst are in the Department of Human Geography and Planning, Faculty of Geosciences, Utrecht University, PO Box 80.115, Utrecht 3508 TC, The Netherlands. Email: j.brands@uu.nl and i.vanaalst@uu.nl.

Tim Schwanen is in the Transport Studies Unit, School of Geography and the Environment, University of Oxford, South Parks Road, Oxford, OX1 3QY, UK. Email: tim.schwanen@ ouce.ox.ac.uk. 
creation of safe and enjoyable spaces without fear will attract more visitors and consumer spending (Helms, 2008). The inclination to mitigate fear of crime is particularly strong in the context of the NTE because of the discourses regarding (binge) drinking, vandalism and disorder that surround urban nightlife (Jayne et al., 2008). The most common governmental strategy to mitigate fear of crime and regulate the NTE has been the intensification of surveillance and policing (Cook and Whowell, 2011; Roberts and Eldridge, 2009): video surveillance, more police officers and private security guards, zero-tolerance policing, stricter law enforcement, more lighting and physical designs that provide orderliness and overview.

Interventions through lighting and physical design align with situational crime prevention (SCP) scholarship (Clarke, 1995). This includes Newman's (1973) 'defensible space' theory, the 'crime prevention through environmental design' approach (Cozens, 2002) and 'prospect-refuge-escape theory' (Fisher and Nasar, 1992). Linked to this research tradition is Wilson and Kelling's (1982) 'broken windows' thesis, which focuses on how dilapidation creates free spaces for unwanted behaviour and so triggers fear. Central to SCP thinking is the assumption that alterations to the physical environment will bring about social change and thereby reduce fear of crime. The broken windows logic is also a key legitimisation for zero-tolerance, hot spot and other policing strategies (Bannister et al., 2006: Hinkle and Weisburd, 2008): it is believed that the presumed downward spiral of greater fear of crime, reduced informal control and sense of community, more crime and a worsening reputation of a site is halted if (what are widely constructed as) disorder and incivilities_-graffiti, panhandling, littering, alcohol-fuelled brawling, etc.-are tackled in a co-ordinated manner.
Nonetheless, the effectiveness of zero-tolerance policing and interventions aligned to SCP scholarship in reducing fear of crime is not uncontested. The link between policing and fear of crime has received scant attention in the geography literature, but feminist geographers have criticised SCP thinking pre-dating geographers' increased attention for emotions and affect over the past decade (Koskela, 1997; Mehta and Bondi, 1999). SCP thinking has been criticised for assuming mechanistic effects of environmental stimuli, positioning fearful individuals as passive and lacking agency, and disregarding systematic differences between individuals in the skills, resources, preferences and intuition that shape people's dealing with fear.

In fact, feminist geographers have been key protagonists of a socially/culturally constructivist perspective on fear of crime that shifts explanations from environmental causes to the socially constructed meanings inscribed into the environment. People, the argument goes, have come to fear darkness, the night, strangers, men and parks through social learning and exposure to media discourses, rumours and second-hand experience (Koskela, 1997; Mehta and Bondi, 1999). Fear is thus entwined with "the local details of individuals' circumstances and life courses [and is] sensitive to spatial, temporal and social contexts" (Koskela and Pain, 2000 , p. 271). Yet, in this constructivist perspective, the active role of materiality in the emergence of fear of crime is sidelined and the situatedness of fear in the continuous flow of practice can also be backgrounded. Hence, and in keeping with broader sentiments in cultural geography, Pain (2006) has argued for 'rematerialising' fear of crime: researchers should emphasise tangible experiences and the impacts of fear and crime on people's everyday lives, ground those experiences in particular places and their materiality, and examine how such life 
circumstances as socioeconomic position and gender structure material experiences.

In this paper, we complement Pain's material approach to fear of crime by taking inspiration from non-representational and assemblage theories (Anderson et al., 2012; Thrift, 2007) in order to bring together SCP and socially/culturally constructivist perspectives on fear of crime and to highlight the role of ambiguity in the generation of such fear. Our objective is to analyse fear of crime as an event that emerges from the ongoing assembling of associations among human and non-human, material and discursive elements, and to examine how nightlife visitors reflect on the roles of lighting, policing and 'undesired others' within emergent assemblages. As the roles and effects of elements within such assemblages are always potentially unstable, we pay particular attention to the ambiguities that can occur with regard to lighting, policing and 'undesired others' in the generation or reduction of fear of crime.

We utilise semi-structured interviews structured around photo elicitation with university students in Utrecht, The Netherlands, and focus on the streets, squares and alleys in and around nightlife districts because it is here that people from different backgrounds encounter each other and many incivilities-fuelled by alcohol use or otherwise-occur (Crawford and Flint, 2009; Roberts and Eldridge, 2009). Given on-going trends of the hybridisation and privatisation of public space in the Netherlands and elsewhere (Kohn, 2004), many of the streets, squares and alleys we considered are no longer simply public. This blurring of the public/private distinction is also reflected in the 'safe nightlife policies' that many Dutch cities have adopted since around 2000 to regulate their NTE (van Liempt and van Aalst, 2012). These policies are a form of nodal governance (Hadfield, 2008) in which public stakeholders-usually the city council and the police-co-operate with the nightlife industry and private security firms in order to increase visitors' experiences of safety.

\section{Understanding Fear of Crime through Encounters}

\subsection{Emotion and Affect}

Because fear of crime embraces a range of emotions and embodied sensations (Pain, 2000, 2009), we use 'fear of crime' as shorthand for multiple interrelated phenomena of differing intensity-unease, discomfort, anxiety, apprehension and panic-that are united in three ways. They are linked to other fears and anxieties, including those for terrorism or immigration, and other emotions like safety or excitement (Pain, 2009); they are spatiotemporally complex and tie together (and constitute) multiple spatial and temporal scales, from the hereand-now to events earlier in the life-course and "wider networks of power and privilege" (Pain, 2009, p. 475); and they are all embodied, distributed and emergent.

Fear of crime can be studied empirically as embodied, distributed and emergent by drawing on the work of Deleuze and nonrepresentational geography. Following Anderson (2006) and McCormack (2008), we can analyse fear of crime as experienced in and through one's corporeal body as visceral and proprioceptive modulations-feelings-like a knot in the stomach or a tremor. These feelings can be put in words in a qualified and personalised form as an emotion, as with 'I feel uneasy'. Feelings also have transindividual affective dimensions, which pertain to the relations between a person's corporeal body and other agents. They refer to the capacity of a body-here used in a generalised sense as any set of material or discursive elements held together by 
"relations of motion and rest, of speeds and slownesses" (Deleuze, 1988, p. 123) ${ }^{1}$ - to affect and be affected by other bodies. Empirical studies of fear of crime should thus consider affective relations among entities and focus on the assemblages-nonhomogeneous and continuously changing ('assembling') constellations of people, artefacts, words, symbols, memories and so forth ( Anderson et al., 2012; Deleuze and Guattari, 1987) - in which fear of crime inheres. Fear of crime needs to be studied as belonging to both the perceiving subject and the assemblage in which s/he is embedded.

\subsection{Triggers and Ambiguity}

Studying fear of crime in the NTE from the perspective of assemblage thinking comes with two specific advantages. As assemblage thinking does not privilege the material over the discursive (or vice versa), it allows analysts to explore how both socially learnt discourses and specific, changing configurations of materiality are implicated in fear of crime. It thus offers a way of connecting SCP scholarship and the constructivist approaches from feminist geography within a framework of non-deterministic, non-linear causality. Assemblage thinking can act as connecting device because Deleuze (1988) foregrounds the significance of concrete encounters between bodies (in a generalised sense) as part of the continuous flow of practices to the emergence of affects and the increase or diminution of a body's capacities to act.

A Deleuzian perspective also highlights that triggers of fear of crime are emergent rather than pre-given. What triggers fear differs not simply from person to person, but also between unfolding situations. As Spinoza wrote

Different men [sic] can be affected differently by one and the same object; and one and the same man $[$ sic] can be affected differently at different times by one and the same object (Spinoza, 1996, III/178, p. 51).

This has to some extent been recognised in the geography of fear literature, given that Pain (2000) and others have acknowledged that street light can increase control and safety through the vision and prospect it affords but may equally accentuate and reveal signs of disorder at different times for the self-same individuals. A key reason why empirical research into fear of crime can benefit from assemblage theory is that it offers the conceptual tools to understand and foreground ambiguity-the lack of a stable, well-determined effect-in terms of what 'causes' fear of crime.

To understand such ambiguity, we need to seek explanations of the generation, intensification or reduction of fear of crime that are immanent to encounters. Instead of invoking general principles or situationtranscending explanations, researchers should adopt what Stengers (2010) calls an ecological sensibility during fieldwork and analysis. This means not only that analysts should refrain from understanding inanimate materiality as "a silent world, the docile substrate of convictions and interpretations" (Stengers, 2010, p. 40) and foreground its active role within assemblages and the generation of fear of crime; they should also examine if and how the roles that various human and non-human elements in a given assemblage play are 'metastable'-i.e. shift and change when the composition or character of the assemblage changes (through the process of 'assembling'). Thus, whilst light often reduces fear of crime among people in public spaces at night (Painter, 1996), it is also possible that a person who moves from the dark into a circle of light created by a lamp-post experiences anxiety as what happens beyond that circle is rendered extra dark and invisible (see also Morris, 2011). For assemblage 
thinkers, ambiguity is an irreducible part of assemblages, encounters and the on-going generation, intensification and reduction of fear of crime, and empirical research should make clear if and how ambiguities emerge and evolve.

\subsection{Entangling Time and Space: Memory and Futurity}

The preceding discussion lacks temporal depth: it focuses on short-term dynamics and is vulnerable to the criticism of 'presentism' sometimes levelled at non-representational geography (Rose et al., 2010). Considering how memory and a person's past experience mediate the ways in which fear of crime brings the future into the present not only avoids such presentism, it also provides a further means to analyse how ambiguity may be central to the generation, intensification and reduction of fear of crime. In this context, we can mobilise Bergson's (1912) habit-memory and pure memory as analytical tools. The former consists of automatic behaviours and sensori-motor mechanisms. Bodily comportments - in many ways gendered, racialised or otherwise socially differentiated (Simonsen, 2013)_exemplify this habitmemory and matter to fear of crime. Not only can their performance at a particular site in a nightlife district engender fear in others, they also shape fear of crime via perception: how we perceive an encounter is formatted by sensori-motor mechanisms acquired over one's life-course (Connolly, 2011).

For Bergson, pure memory pertains to the unconscious survival of personal memories through which the past is progressively carried forward into the present, and can become part of embodied action in a specific encounter. This view on memory helps us understand how victimisation and socialisation $^{2}$ over the life-course-whose significance has been recognised widely in the geographies of fear literature (Koskela and Pain, 2000; Mehta and Bondi, 1999)_continues to shape people's experience of fear of crime. Through attention for the role of memory scholars can understand how fear of crime as produced in assemblages at specific sites and times bears traces of political discourses, cultural values, rumours, stereotypes and prejudices (re)produced through social institutions (Pain, 2009). Because individuals differ in terms of the internalisation of these discourses, values and so forth, their capacities to be affected by other elements in particular encounters are also differentiated. Hence, an analysis of ambiguities in the effects of encountered elements-for example, policing practices or other consumers' comportments-on fear of crime demands that attention be directed towards the folding of past experiences into the present.

The future also matters to fear of crime as fear concerns the not-yet. Given fear's intrinsic future orientation, empirical research into the fear of crime should also consider futurity. Whatever its trigger, fear of crime tends to suspend the ways in which the past (through habit-memory) propels people into the immediate future: they no longer know how to go on, but experience orientational difficulties whereby their 'action-guiding anticipations' (Shotter, 2009) - the unreflective, spontaneous and anticipatory responsiveness to the assemblage they are enmeshed in-are disrupted. One example of this is people freezing when becoming fearful; another is the triggering of cognitive thought about the range of immediate futures that might unfold-some of which might involve harm or injuryand about what to do. Herein lies another source of ambiguity: a certain element might reduce the possibility of harm and fear of crime yet also increase these, depending on how the assembling of elements unfolds and the present progresses in time. 
This can be illustrated with reference to critical policing studies (Cook and Whowhell, 2011; Hinkle and Weisburd, 2008) arguing that police presence in public places not only reassures members of the public but can also-and simultaneously among the same individuals-raise awareness that danger is imminent.

\subsection{Towards the Empirical Analysis}

We propose to analyse fear of crime in the NTE as an event-a diminution of and shift in the corporeal body's capacity to orientate itself spontaneously towards the immediate future-that unfolds as part of the on-going encounters and assembling of elements in particular sites of which individuals are necessarily part. Whether fear emerges, intensifies or is reduced is subject to ambiguity. Three forms of ambiguity, defined as the absence of stable and welldetermined effects, can be identified

(1) Different individuals responding differently to a particular element within assemblages, among others because of the unique-and gendered, racialised or otherwise differentiated-memories they have accumulated over the lifecourse.

(2) The same individual responding differently to a particular element in different situation because it is part of a different assemblage and its role therein is only meta-stable.

(3) The same individual responding in multiple ways to a particular element in a specific situation frozen in time because the element helps to open up different futures.

Two questions for empirical research follow from this and will be addressed in what follows. Can these forms of ambiguity be identified with regard to fear of crime and the
NTE? If so, what are the elements that trigger these affective ambiguities on a night out?

\section{Research Design}

\subsection{Context}

Our empirical analysis is situated in Utrecht - a historic city with a population of $\pm 316,000$ inhabitants, in The Netherlands. Nightlife facilities are clustered in the city centre, consisting of a mix of restaurant, cinemas, (small) pubs and clubs without strict 'closing times' or regulation of alcohol sales (Schwanen et al., 2012). Utrecht was selected because it is the fifth-largest city in The Netherlands and one of the first to develop and implement Safe Nightlife Policies (van Liempt and van Aalst, 2012). Since 2001 the city council has implemented a broad variety of 'safe nightlife' measures, even though the ratio of instances of crime to the number of consumers in the nightlife districts was low given the city's size and compared with other Dutch cities (Snippe et al., 2006). The central nightlife district is covered by many CCTV cameras, complemented with on-site patrolling of a special 'nightlife team' of police officers working together with pub and club owners (see van Liempt and van Aalst, 2012, for further details).

Utrecht has a young population, with many inhabitants under 18 years (20 per cent) and between 18 and 26 years (19 per cent), mainly due to the presence of a large university. According to the city's website, almost half of the population of 16 years and older is highly educated (at least a bachelor degree or equivalent) and 22 per cent of the city's inhabitants are of non-Western descent. ${ }^{3}$ Our previous research has shown that the nightlife district in Utrecht is disproportionally White compared with the city's resident population (Schwanen et al., 2012): only 11 per cent of the consumers in the 
NTE were of non-White extraction. The Whiteness of Utrecht's NTE primarily reflects the supply of bars and clubs, which are oriented strongly towards highly educated (White) students and young urban professionals who live in/around the city.

\subsection{Participants}

For this study, we concentrated on people who actually participate in Utrecht's NTE as they are likely to have detailed knowledge of whether and where fear of crime is experienced over the course of a night out in Utrecht and what triggers such fear. To attract people who participate regularly in Utrecht's NTE, we centred recruitment efforts on students aged 18-25 at three student housing complexes: Ina Boudier Bakkerlaan in the city centre, Uithof on the fringe of the city and suburban Warande. Students were recruited by asking passersby on streets in each complex whether they wanted to participate, via posters in residential buildings and through snowball sampling techniques. We sought to vary our sample in terms of gender and recruited 18 females and 12 males. All 30 respondents were in (applied) university education and considered themselves 'Dutch' although one participant was born in Brazil. Of course, including older participants, with other levels of educational attainment and/ or persons from other ethnic backgrounds would have yielded additional insights, but it would also have made the analysis less specifically tied to the unfolding situations characteristic of Utrecht's nightlife.

\subsection{Interviews}

Every participant was interviewed three times over the Spring of 2009 with each interview attempting to answer specific research questions. This study relies on the third interview, but was informed by the earlier interviews in two ways. The first two interviews helped in creating trust and rapport between interviewer and participant, which made discussing fear of crime in the third interview much easier and enabled more intimate conversations than would have been possible otherwise. Additionally, the second interview covered the participants' familiarity with, local knowledge of, and activities undertaken in, Utrecht's city centre and nightlife district. This information was of great aid in the conduct and analysis of the third interview.

The interviews were conducted by four different persons (all White, in their 20s, two males and two females); each interviewer interviewed participants of the same sex with the idea that this might stimulate participants to discuss gender-specific and/ or intimate experiences. The participants themselves chose where the interview took place. All interviewers considered that participants had spoken to them freely and without reservations. The interviews lasted 45-60 minutes and were audio-taped with participants' informed consent.

Two techniques helped to enrich the participants' narratives during the interviews. One was the use of photos, which were used not as stable, already finished visual panoramas, but as prompts inviting participants to imagine themselves as enmeshed in the nightscapes depicted. The other technique was to ask participants how onprettig or prettig they would feel when participating in the pictured nightscape on a 7-point likert scale $(-3$ to +3$)$. These words are best translated as uncomfortable or comfortable, but cover a wider range of emotions. This framing, which is more neutral than fearful versus not fearful, was preferred as preliminary research had suggested that students used onprettig more frequently than fearful or anxious to describe their embodied responses to photos of urban nightlife. We also hoped that using onprettig rather than 
the literal Dutch translation of fearful [angstig] would lower participants' reticence to articulating more negative emotions.

We opted for photos taken by us to ensure a basic level of comparability across situations and persons. We selected six photos depicting scenes from the NTE in Utrecht's city centre which we expected to generate affects and emotions relevant to the fear of crime literature. Since social and environmental causes of fear of crime cannot be neatly separated (Koskela and Pain, 2000), each photo depicts specific physical elements to which a range of socially constructed and shared meanings are likely to be linked (see Figure 1)

- Photo 1 depicts various sources of lighting; these are widely considered to increase safety as they enable prospect (allowing others to be seen) and the possibility of natural surveillance by residents.

- Photo 2 depicts an easily recognisable empty square, with graffiti paintings. Both Utrecht's safe nightlife policy and the 'broken windows' thesis hold that graffiti-and dilapidation more broadlycreate free spaces for unwanted behaviour and trigger fear.

- Photo 3 captures differences in lighting and depicts a route through a park-a class of site that is often socially constructed as dangerous at night (Koskela, 1997) — that many students in Utrecht use to access the city centre.

- Photo 4 depicts a person whose bodily comportment and/or dress style might engender fear of crime, with the narrow alley drawing extra attention to these factors.

- Photo 5 shows a range of nightlife facilities positioned around a spacious square with NTE consumers passing by. It intends to capture the continental European ambiance which many local councils in the UK have sought to emulate through NTE policies (Roberts and Eldrige, 2009).

- Photo 6 depicts two bars and a police patrol. The police car is noteworthy as preliminary research among NTE consumers had shown that police officers in cars often evoked strong emotional responses.

All interviews were transcribed verbatim and were subjected to multiple rounds of open and axial coding (Corbin and Strauss, 2008). We first identified elements that triggered experiences of safety and fear of crime among interviewees and then drew out ambiguities in the generation and diminution of fear of crime.

The use of interviews over some form of mobile method (Büscher and Urry, 2009) is potentially problematic in light of the view of many non-representational geographers that interviews provide at best an incomplete and deadened after-the-fact account of what took place (Thrift, 2007). Yet, based on our own experiences and the comments by Hitchings (2012), we feel that our participants were quite capable of talking about their emotions, triggers of fear of crime and their nightlife practices and experiences. Nevertheless, we readily acknowledge that our interviews foreground some aspects of fear of crime and triggers whilst backgrounding others (but this holds for any method). For instance, only those triggers of feelings that have crossed the threshold of consciousness can be discussed in interviews, meaning that triggers that operate at pre- or subconscious levels will have been excluded. Yet, the interviews seem to have captured how memory-both personal memories and aspects of socialisationshapes experiences on nights out rather well. Careful analysis of participants' words also enabled us to understand at least some of the ambiguities associated with the triggers of feelings and emotions. 


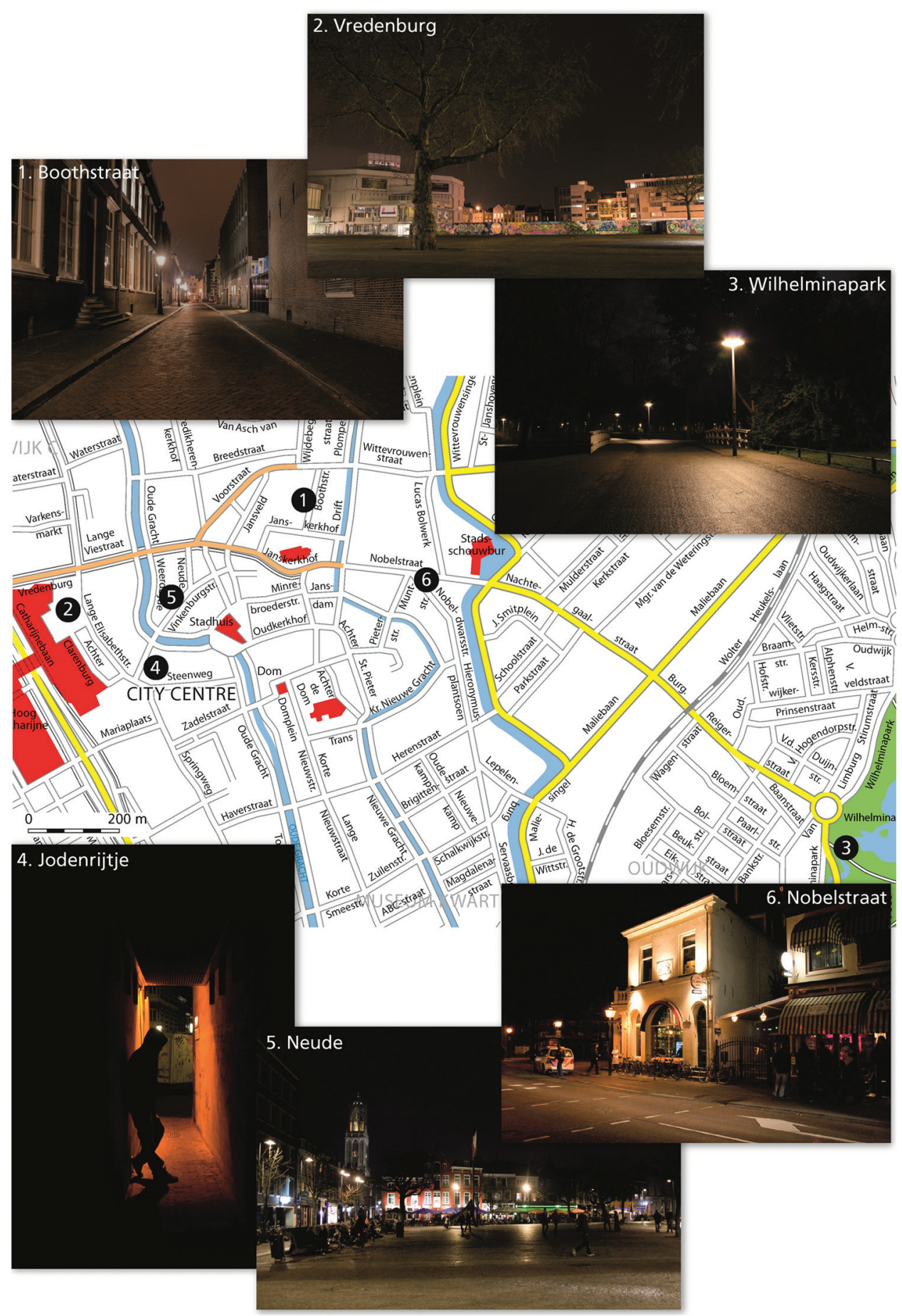

Figure 1. Photos and their location in the city of Utrecht. 
Table 1. Average levels of comfort/discomfort per photo, by gender and residential location

\begin{tabular}{|c|c|c|c|c|c|c|}
\hline & $\begin{array}{l}\text { 1: Booth- } \\
\text { straat }\end{array}$ & $\begin{array}{l}\text { 2: Vreden- } \\
\text { burg }\end{array}$ & $\begin{array}{l}\text { 3: Wilhelmina- } \\
\text { park }\end{array}$ & $\begin{array}{l}\text { 4: Joden- } \\
\text { rijtje }\end{array}$ & 5: Neude & 6: Nobelstraat \\
\hline \multicolumn{7}{|l|}{ Gender } \\
\hline Male & 1.4 & 1.0 & 0.0 & -1.4 & 1.8 & 1.0 \\
\hline Female & 0.2 & 0.2 & -1.4 & -2.8 & 1.9 & 1.4 \\
\hline $\begin{array}{l}p \text {-value for } \\
\text { Mann-Whitney test }{ }^{a}\end{array}$ & 0.018 & 0.179 & 0.007 & $<0.001$ & 0.723 & 0.611 \\
\hline \multicolumn{7}{|l|}{ Location } \\
\hline IBB & 1.2 & 1.0 & -0.8 & -2.1 & 1.8 & 0.9 \\
\hline Uithof & 1.1 & 1.0 & -0.2 & -2.0 & 2.0 & 1.6 \\
\hline Warande & -0.20 & -0.4 & -1.6 & -2.6 & 1.7 & 1.1 \\
\hline $\begin{array}{l}p \text {-value for } \\
\text { Kruskall-Wallis test }^{\mathrm{a}}\end{array}$ & 0.051 & 0.059 & 0.085 & 0.224 & 0.808 & 0.317 \\
\hline All participants & 0.7 & 0.6 & -0.8 & -2.2 & 1.8 & 1.2 \\
\hline
\end{tabular}

${ }^{a}$ If $p<0.05$, the gender/locational difference for a given picture is statistically significant at a 95 per cent confidence level.

Note: Participants were asked to express how comfortable (prettig) or uncomfortable (onprettig) they would feel if they were part of the depicted assemblage, using a seven-point $(-3$ to +3$)$ Likert-type scale where -3 equalled very uncomfortable, 0 neither comfortable nor uncomfortable and +3 very comfortable (see section 3.3 ).

\section{Understanding Fear of Crime in the Night-time Economy}

The 30 participants responded quite differently to the situations depicted in the six photographs. Photos 6 and especially 5 generated the highest level of comfort; photo 3 and particularly photo 4 generated the most discomfort (Table 1). There was a clear difference between male and female participants because the latter experienced photos 4,3 and 1 as considerably more uncomfortable. This concurs with the extensive literature on gender differences in fear of crime in public spaces (Koskela and Pain, 2000; Whitzman, 2007). On the whole, however, gender differences were less profound than anticipated. This might reflect the relatively privileged social position - university students - of the female participants. There were also clear differences between the three housing complexes with participants from suburban
Warande feeling more uncomfortable with the nightscapes in the first three photos.

Nonetheless, the photos' primary purpose was to prompt participants to discuss elements that generate or diminish fear of crime. The use of the photos was successful as many such elements were discussed by the participants and the interviews showed clearly that those elements were enmeshed in assemblages and that their roles could not be understood in isolation from those assemblages. Here we focus on three particular elements-lighting, policing and others encountered in nightlife situations-as study participants singled these out most frequently in relation to the generation or reduction of fear of crime.

\subsection{Lighting}

Consistent with previous studies (Painter, 1996), the participants felt that lighting 
tends to reduce fear of crime in the context of Utrecht's NTE. Ambiguities across persons and situations (photos) in the effects co-produced by lighting were limited. This is a noticeable result, given the differences in lamps and in intensity, colour, texture and distribution of light across the photos. Three sets of processes tended to generate the generally positive experiences of lighting. First, the participants felt that light was related to who might be present in a particular place. It 'normalised' a site by deterring potential wrongdoers and produced safety in numbers as it meant more intensive use of streets after dark (Painter, 1996). As Willy ${ }^{4}$ exclaimed, "Surely they don't put a lamp-post there if nobody ever visits!" Secondly, several participants felt that light in conjunction with bars and 'normal' people created an atmosphere of conviviality. This was discussed specifically in connection to photos 5 and 6 , which depict two well-known sites with student-oriented bars in Utrecht. Closer analysis suggests that the familiarity of these nightscapes also played a role in how participants experienced and discussed the light and indeed the larger assemblage captured within those snapshot pictures. This in turn suggests that it is not only the momentary 'presentism' of an assemblage that was relevant; memories became part of the assemblage and its experience.

The third and most important process was that light afforded visibility in the sense of an overview of the (moving) bodies close to one's own corporeal body. By assisting in the identification and signification of individual bodies, it also co-produced visibility in another way

The idea that you have to pass that, poorly lit, guy in the dark ... and such a small passage I wouldn't find enjoyable ... If there is enough light so that you can just see that guy, then you can assess [the situation] better and it will improve ... yeah, I can't see it in the dark, so it is difficult to assess (William, on photo 4).

For William and others, light aids in the anticipation of immediate futures: it reduces the risk of assault (Painter, 1996; Pain et al., 2006), or at least makes it more manageable at both conscious and unconscious levels. The interviews make it clear that darkness in NTE settings increases orientational difficulties, unsettling people's action-guiding anticipations (Shotter, 2009). It implies unknowability-the "big dark unknown around you" (Wayne)—and hence a distinctive futurity. Discussing photo 3, Ursel explains

Look how dark it is there, there and there [pointing to sites near the road on the photo]. You don't know at all who is hiding behind these shrubs and if there is someone-probably not ... you have no idea, someone might be a few metres away and you just can't see it.

Lighting, then, was believed to reveal potential wrongdoers and to make some futures that could spring from encounters in the unfolding present less likely, making public spaces in NTE settings more enjoyable and secure. There nonetheless resides ambiguity in the effects of light: being illuminated raises one's own vulnerability as a "person does see [you] since you are cycling in the light, but he is not in the light" (Ushi). In such a situation, light not only enables potential wrongdoers to take advantage of how lighting illuminates a victim-to-be; it also makes potential wrongdoers more invisible for a potential victim by intensifying darkness. Having just moved from the dark into the light, potential victims have to adjust their eyesight when a 'bubble' effect (Morris, 2011, p. 322) occurs: rather than affording an expanded field of vision, the lamp-post encloses him/her in a circle of 
light beyond which the dark is extra dark. The distribution of light matters here, for bubble effects are more intense when circles of light are located in a sea of darkness, as in photo 3 .

A second ambiguity regarding the effects of light was observed in connection to photo 2, which depicts a well-known square that attracts many pedestrians at night. Many participants were positive about the lighting but responses revealed more ambiguity than with photos 5 and 6 as some participants felt the lighting helped to reduce comfort levels. As Wayne said, "that graffiti and those sharp lights there, it all makes it a bit sinister". This second ambiguity is different from the first and represents type a) in Sub-Section 2.4. The first ambiguity, however, occurred in one and the same encounter for one and the same person and thus corresponds to type c). For lighting this type could be identified only among several participants, but it was more prevalent with regard to police presence.

\subsection{Police}

Comments on police officers were made mostly in relation to photo 6 . About onethird of the study participants attributed only positive effects to police presence on fear of crime, and a few attributed little effect to policing. Yet, more participants than anticipated articulated ambiguity within one and the same situation

But then you see the police standing there and you think: well yeah, that is a bit ambiguous. For on one hand, I think, yeah, it gives some sense of security, police in the vicinity. On the other, I think well why are they here? Is there something? (Urmela, on photo 6).

Well I always feel that police are there for a reason. Look if it wouldn't be necessary, the police wouldn't be there ... Apparently something is going on there. Yeah, or apparently they think things can go out of hand or something, you know ... But then again it is night out, so they can also be just on surveillance (Umara, on photo 6).

Interviewees like Urmela and Umara confirmed the earlier claim that police presence triggers more than comfort among 'wellbehaved' consumers in the NTE. Whilst making certain immediate futures less likely, police presence also and simultaneously brought other possible futures into consciousness: it reminded the well-behaved of the immanent possibility that things can go out of hand. Both from first-hand experience and through exposure to global discourses about intoxication, the urban night and specific nightlife establishments, participants in our study were well aware that anger/rage, love, jealousy, etc. are more intense at night and that the encounters with elements in the assemblages depicted in photos 5 and 6 can spiral into commotion more rapidly than during daytime.

In the quote, Umara expresses not simply uncertainty about what might happen but also uncertainty if something (unpleasant) might happen or whether the police are simply on surveillance. This ambiguity triggers not only orientational difficulties, but also a cognitive reorientation towards the assemblage of which she is part and through which a (near) future of disorder becomes imagined. The practices and appearance of police officers to some extent influence whether such reorientation occurs. Ursula, for instance, tended to appreciate visible police presence because of its preventative effects and capacity to intervene when something happens. Yet she also intimated that if she arrived at the square depicted in photo 5 and saw five police officers, she would consider this disproportionate and "think what the $\mathrm{f}^{* * *}$ is going on here?". Responses like Ursula's align with findings reported 
elsewhere (Brands and Schwanen, forthcoming) that policing practices in the NTE-whether officers are on foot or rather on horse-back or sat in cars, and whether they are wearing batons or reflective vestsshape NTE participants' experiences of safety. More than simple police presence, it is policing-as-practice that has an influence on fear of crime (see Cook and Whowell, 2011).

\subsection{Others}

Discussing photos 4 and 6, participants brought up multiple ambiguities across persons, across situations and for single participants in one and the same encounter. Some were highly appreciative of the crowd in front of the depicted student-oriented bar in photo 6

I don't know why I should feel unsafe here. It is just a student bar. I know how those bars are, just attract a nice crowd, I think (Uriel).

Of course it is often drunk people who stand outside but I always like it when there are many people ... well, you think, that is cosy [gezellig], you know (Ulla).

Uriel highlights how affective encounters with other nightlife consumers are mediated by memory; his knowledge has accrued from both first-hand experience and wider socialisation processes with stereotypes developed over time mediating perception and experience (Connolly, 2011). The ability to identify with the crowd and their practices narrows down the range of (un)consciously anticipated immediate futures, and therefore ambiguity, to such a degree that drunk others are felt to be manageable risk or no risk at all. Whilst encountering crowds, as in photo 6 , created few orientational difficulties for Uriel and Ulla, other participants expressed more reservations. Wanda, for instance, was more cautious in this particular nightlife setting and imagined a more diverse range of immediate futures. Her unconscious and conscious anticipations appeared less entrenched than Uriel's and Ulla's because she singled out other elements as relevant within the assemblage and was less familiar with the particular bar that was depicted

It appears to be a bar with people standing outside and certainly in such a situation with police being there you just expect well they are probably there 'cause there are annoying people walking around ... There are also people who have been drinking, doesn't have to be negative, can also be cute, o well (Wanda).

Ambiguities were more profound in relation to photo 4, which participants generally perceived as threatening. The threatening atmosphere was associated with the unusual combination of underdetermination and overdetermination that characterises photo 4. The underdetermination-lack of clarity about what the depicted person might do and hence what immediate future may unfold-was expressed through the ways in which participants discussed the invisibility of the person and his/her face

'Cause it's so dark and you just can't see anything of that very person, except that he wears a hood, but no face or something, you can't see how old he is. I think it's a man but maybe it's woman. Yeah you really can't get an impression (Whitney).

Resonating with Thrift's (2007) emphasis on the face as a key affective site, Whitney's remarks highlight the importance of facial expressions to how likely immediate futures are imagined and to triggering fear for others.

The participants clearly disliked the underdetermination characterising photo 4 
because it unsettled their capacities to anticipate the future and made them uncomfortable. Employing Bergson's concept of pure memory also helps to observe a second effect: it illustrates how a lack of information on the depicted body results in the mobilisation of stereotypes, acquired over the lifecourse, to make sense of the particular encounter. For Inez the person was "a junk with a hoodie" and Immanuel made similar comments

It is a bit of a stereotypical image of people with hoodies hanging [in such places]. Yeah people who're after your wallet or whatever ... It need not be a junk or a beggar. It can be a little pain in the neck too. And look, if a bloke in a suit or something with a tie stood there (laughs), then you'd pass quite differently (Immanuel).

These stereotypes do more than reduce the encountered body's underdetermination. They simultaneously increase the participants' sense of discomfort through overdetermination as they predisposed the participants towards immediate futures of harm or hurt over other possibilities (for example, the person stepping aside and nodding in a friendly way when somebody would like to pass) and so co-created or intensified fear of crime.

As expected, feelings of discomfort were intensified by the specific qualities and capacities of the alley depicted in photo 4 : its narrowness, which makes evasion or escape difficult; the lack of light; the absence of 'normal' others who might come to one's aid; and the absence of vibrant nightlife at the end of the alley. This implies that attempts to understand what triggers fear of crime should resist the tendency to isolate or abstract persons from the assemblages of which they are part: fear of crime was triggered not simply by the depicted corporeal body, its age, gender, clothing or comportment, but by the wider bodyassemblage. For some participants the experience would have been different had the encountered assemblage been different

Interviewer: And what if we positioned this person to, say, that tree on the Vredenburg? (see photo 2).

Ulla: Oh, then I wouldn't mind so much. Yeah then it's not such a-here you can only pass him, but there you can traverse that square in many other ways ... Here there is no other opportunity.

\section{Final Remarks}

Arguing that fear of crime is an event, we have analysed if and how ambiguity-the absence of stable, well-determined effectscan be identified regarding how lighting, policing and 'undesired others' help to shape fear of crime during young adults' participation in a city centre's night-time economy. The empirical analysis among university students in Utrecht has confirmed that ambiguities are an inevitable part of the experience of fear of crime on nights out, as well as the usefulness of distinguishing three types of ambiguity: across persons in a given situation, across situations for a given person, and for a single person in one and the same situation. However, the empirical analysis extends the analytical framework outlined in section 2 by showing that, among the participating university students, the occurrence of ambiguity differs between lighting, policing and 'undesired others': the fear-reducing effects of lighting were least ambiguous across persons and situations, whilst ambiguities for a single person in one and the same encounter were most widespread for policing practices.

The empirical analysis has also corroborated the importance of temporal depth to 
understanding fear of crime and ambiguities in a NTE setting: the question of which human and non-human elements in a person's close proximity trigger fear cannot be answered without due attention for how past and future are enfolded in the present. Among the study participants, the third type of ambiguity-that for a single person in one and the same situation-tended to result from different, often incompatible, immediate futures being folded into a particular present. Their habit-memory and pure memory (Bergson, 1912) explained to a considerable degree which futures showed up with the greatest force in a present.

Moreover, the empirical analysis endorses the theoretical notions in section 2 and contributes to feminist thinking in fear of crime by suggesting that it was via the interlocking of past, present and future that gender (and class and race) shaped fear of crime and the associated ambiguities. Gender primarily had indirect effects on fear of crime during participation in the NTE by influencing which habit-memories and pure memories study participants had accrued over their life-course and what they considered to constitute a threat or source of potential harm. Some differences between male and female participants were observed (Table 1), but those were smaller and less frequent than expected on the basis of the existing literature (Pain, 2000; Whitzman, 2007). This is in part due to our focus on highly educated and White young adults who can afford to participate and feel welcome in Utrecht's nightlife premises.

The conclusion that ambiguities in the generation, intensification and reduction of fear of crime are inevitable has significant policy implications: the opposition of stressors or causes of fear of crime vis-à-vis remedies needs to be suspended because this dualism clouds our understanding of fear of crime. This does not imply that policy interventions to reduce fear of crime in urban nightlife are futile. We rather believe that policy-makers, researchers and others seeking to reduce fear of crime should move away from thinking about 'lighting', 'police presence' or 'undesired others' as generic, abstract categories.

One alternative would be to think about the particular qualities and capacities of lighting and how it can be made 'smarter' in specific locales. This means addressing questions for specific sites in/around nightlife districts. For example, if lighting at this particular site helps to reduce fear of crime by making certain places visible, does it not simultaneously also cover other events in darkness and so co-produce new threats? How can this specific site be illuminated without making passers-by more vulnerable? A potentially useful policy option, put forward by some study participants in connection with photo 3 , consists of lighting a buffer zone of shrubbery or other places where people might be hiding along paths or routes for walking or cycling. This would enhance NTE participants' sense of control, reducing uncertainty about immediate futures and orientational difficulties. It would also be important to reconsider policing practices-especially the number of officers patrolling the streets and the equipment they carry - as these can both reduce and generate or intensify fear of crime among NTE consumers. For instance, consumers tend to prefer officers on foot or on bike over patrols on horseback or in cars, amongst others because the latter practices make futures of harm or disorder show up more forcefully at the moment of encounter. Finally, stereotypes-a form of memoryplay an important part in the enfolding of futures in the present and thereby the way NTE consumers make sense of encounters with other human beings and the generation of fear of crime. Whilst it is difficult to influence stereotypes through (local) policy, it is important to make sure that policy 
initiatives do not unintentionally reproduce or strengthen them.

\section{Acknowledgements}

The authors thank the study participants for their time and contribution, and the referees for their helpful comments on earlier versions of this manuscript.

\section{Funding}

This research is financed by the Netherlands Organization for Scientific Research (NWO), grant MVI-313-99-140.

\section{Notes}

1. A human corporeal body is only one manifestation of a body, so is a plant, rain, an idea or a corpus of academic studies. Here, we use 'corporeal body' to refer to the human physical body and 'body in a generalised sense' or 'body-assemblage' for the generic concept.

2. This refers both to 'local' processes, such as parental influence, and to exposure to 'global' discourses about women's vulnerability, the 'Other' and the night as a time of transgression that circulate through the media.

3. See: www.utrecht.nl.

4. Pseudonyms are used to ensure participants' anonymity. The pseudonyms reveal their gender and the first letter also the student complex where they lived at the time of the interview (I for Ina Boudier Bakkerlaan, U for Uithof, W for Warande).

\section{References}

Anderson, B. (2006) Becoming and being hopeful: towards a theory of affect, Environment and Planning D, 24, pp. 733-752.

Anderson, B., Kearnes, M., McFarlane, C. and Swanton, D. (2012) On assemblages and geography, Dialogues in Human Geography, 2, pp. 171-189.

Bannister, J., Fyfe, N. and Kearns, A. (2006) Respectable or respectful? (In)civility and the city, Urban Studies, 43, pp. 919-937.

Bergson, H. (1912) Matter and Memory. London: George Allen \& Co.
Brands, J. and Schwanen, T. (forthcoming) Experiencing and governing safety in the night-time economy: nurturing the state of being carefree, Emotion, Space and Society.

Büscher, M. and Urry, J. (2009) Mobile methods and the empirical, European Journal of Social Theory, 12, pp. 99-116.

Chatterton, P. and Hollands, R. (2003) Urban Nightscapes: Youth Cultures, Pleasure Spaces and Corporate Power. London: Routledge.

Clarke, R. V. (1995) Situational crime prevention, Crime and Justice, 19, pp. 91-150.

Connolly, W. E. (2011) A World of Becoming. Durham, NC: Duke University Press.

Cook, I. R. and Whowhell, M. (2011) Visibility and the policing of public space, Geography Compass, 5, pp. 610-622.

Corbin, J. and Straus, A. (2008) Basics of Qualitative Research. London: Sage.

Cozens, P. M. (2002) Sustainable urban development and crime prevention through environmental design for the British city, Cities, 19, pp. 129-137.

Crawford, A. and Flint, J. (2009) Urban safety, anti-social behaviour and the night-time economy, Criminology \& Criminal Justice, 9, pp. 403-413.

Deleuze, G. (1988) Spinoza: Practical Philosophy. San Francisco, CA: City Lights Books.

Deleuze, G. and Guattari, F. (1987) A Thousand Plateaus: Capitalism and Schizophrenia. London: Continuum.

Fisher, B. S. and Nasar, J. L. (1992) Fear of crime in relation to three exterior site features: prospect, refuge, and escape, Built Environment, 24, pp. 35-65.

Hadfield, P. (2008) From threat to promise: nightclub 'security', governance and consumer elites, British Journal of Criminology, 48, pp. 429-447.

Helms, G. (2008) Towards Safe City Centres? Remaking the Spaces of an Old-industrial City. Aldershot: Ashgate.

Hinkle, J. C. and Weisburd, D. (2008) The irony of broken windows: a micro-place study of the relationship between disorder, focused police crackdowns and fear of crime, Journal of Criminal Justice, 36, pp. 503-512.

Hitchings, R. (2012) People can talk about their practices, Area, 44, pp. 61-67.

Jayne, M., Valentine, G. and Holloway, S. L. (2008) Geographies of alcohol, drinking and 
drunkenness: a review of progress, Progress in Human Geography, 32, pp. 247-263.

Kohn, M. (2004) Brave New Neighborhoods: The Privatization of Public Space. New York: Routledge.

Koskela, H. (1997) 'Bold walk and breakings': women's spatial confidence versus fear of crime, Gender, Place and Culture, 4, pp. 301-319.

Koskela, H. and Pain, R. (2000) Revisiting fear and place: women's fear of attack and the built environment, Geoforum, 31, pp. 269-280.

Liempt, I. van and Aalst, I. van (2012) Urban surveillance and the struggle between safe and exciting nightlife districts, Surveillance and Society, 9, pp. 280-292.

McCormack, D. P. (2008) Geographies for moving bodies: thinking, dancing, spaces, Geography Compass, 2, pp. 1822-1836.

Mehta, A. and Bondi, L. (1999) Embodied discourse: on gender and fear of violence, Gender, Place and Culture, 6, pp. 67-84.

Morris, N. (2011) Night walking: darkness and sensory perception in a night-time landscape installation, Cultural Geographies, 18, pp. 315-342.

Newman, O. (1973) Defensible Space: People and Design in the Violent City. London: Architectural Press.

Pain, R. (2000) Place, social relations, and fear of crime, Progress in Human Geography, 24, pp. 355-388.

Pain, R. (2006) Paranoid parenting? Rematerializing risk and fear for children, Social and Cultural Geography, 7, pp. 221-242.

Pain, R. (2009) Globalized fear? Towards an emotional geopolitics, Progress in Human Geography, 33, pp. 466-486.

Pain, R., MacFarlane, R., Turner, K. and Gill, S. (2006) Qualifying GIS and the effects of streetlighting on crime and fear, Environment and Planning A, 38, pp. 2055-2074.

Painter, K. (1996) The influence of street lighting improvements on crime, fear and pedestrian street use, after dark, Landscape and Urban Planning, 35, pp. 193-201.

Roberts, M. and Eldridge, A. (2009) Planning the Night-time City. Abingdon: Routledge.

Rose, G., Degen, M. and Bagdas, B. (2010) More on 'big things': building events and feelings, Transactions of the Institute of British Geographers, 35, pp. 334-349.

Schwanen, T., Aalst, I. van, Brands, J. and Timan, T. (2012) Rhythms of the night: spatiotemporal inequalities in the night-time economy, Environment and Planning A, 44, pp. 2065-2085.

Shotter, J. (2009) Bateson, double description, todes, and embodiment: preparing activities and their relation to abduction, Journal for the Theory of Social Behaviour, 39, pp. 219-245.

Simonsen, K. (2013) In quest of a new humanism: embodiment, experience and phenomenology as critical geography, Progress in Human Geography, 37, pp. 10-26.

Snippe, J., Hoorn, M. and Bieleman, B. (2006) Convenant Veilig Uitgaan Binnenstad Utrecht Procesevaluatie. Groningen: Intraval.

Spinoza, B. (1996) Ethics, transl. by E. Curley. London: Penguin Books.

Stengers, I. (2010) Cosmopolitics I. Minneapolis, MN: University of Minnesota Press.

Thrift, N. (2007) Non-representational Theory: Space, Politics, Affects. Abingdon: Routledge.

Whitzman, C. (2007) Stuck at the front door: gender, fear of crime and the challenge of creating safer space, Environment and Planning A, 39, pp. 2715-2732.

Wilson, J. Q. and Kelling, G. L. (1982) Broken windows, The Atlantic Monthly, March, pp. 29-38. 